\title{
Efficacy And Safety of Nifuratel-Nystatin in The Treat- ment of Mixed Vaginitis, in Pregnant Women From Quindío, 2013-2017. Randomized Clinical Trial
}

\author{
Franklin J Espitia De La Hoz* \\ Universidad Militar Nueva Granada, Colombia
}

\begin{abstract}
Introduction: Women with abnormal vaginal discharge usually suffer from bacterial vaginosis (BV), vulvovaginal candidiasis (VVC), trichomonas vaginitis (TV) or any combination of these.

Objective: To compare the efficacy and safety of the combination nifuratel-nystatin with metronidazole -nystatin in the treatment of mixed vaginitis in pregnant women, and its adverse effects.

Materials and methods: Randomized, double-blind, parallel-group clinical trial in 153 pregnant women, diagnosed with mixed vaginitis; in a complex private medical institution in Armenia (Colombia), between 2013 and 2017. The patients were randomized 1:1 to receive a daily intravginal egg for six days: nifuratel (500mg) - nystatin (200,000 IU) (Group "A") and metronidazole (500mg) - nystatin (100,000 IU) (Group "B"). A follow-up of the healing of symptoms was determined at one week and an evaluation of the microbiological negativization at one month. Safety was assessed based on reports of adverse events. Descriptive statistics were used.
\end{abstract}

Results: The mean age of the population was $27.59 \pm 3.71$ years. The mean gestational age in group "A" was $18.56 \pm 2.87$ weeks compared to $19.57 \pm 2.95$ weeks in group "B" ( $\mathrm{p}=0.87$ ). The clinical cure rates at 7 days in group "A" were $84.61 \%$ vs. 81.33\% in group "B", (p=0.91) The microbiological negativization at one month was $91.02 \%$ in group "A" vs. $86.66 \%$ in group "B", (p=0,072) The recurrence rate was $1.28 \%$ in group "A" vs. $5.33 \%$ in group "B", ( $\mathrm{p}=0.37)$ Adverse events were present in the metronidazole-nystatin group, which were mild and self-limited.

Conclusion: Both drugs have comparable efficacy and similar safety results in the treatment of mixed vaginitis in pregnant women; therefore, they can be used interchangeably. Studies in larger populations with a control group and random assignment are required to provide better evidence regarding this management.

Keywords: Candidiasis, Vulvovaginal, Trichomonas vaginitis, Vaginosis, Bacterial, Vaginal Discharge, Metronidazole

\section{Introduction}

Vaginitis consists of inflammation and/or infection of the vagina. It is characterized by watery discharge with or without vulvovaginal burning and/or itching. The three most common types of infectious vaginitis are bacterial vaginosis (BV), vulvovaginal candidacies (VVC), and trichomonas vaginitis (TV). ${ }^{1} \mathrm{BV}$, or vaginal symbiosis, is the leading cause of vaginal infection in symptomatic women; with a prevalence of $27.4 \%$, being higher in black women
(33.2\%) and Hispanics (30.7\%). ${ }^{2}$ During pregnancy, its prevalence ranges between $11-29 \% .^{3-5}$ Bacterial Vaginosis (BV) is characterized by a reduction in the population of Lactobacillus spp.; producers of lactic acid and an increase in vaginal $\mathrm{pH}$ with the subsequent growth of facultative and anaerobic bacteria. ${ }^{6}$ It is associated with adverse outcomes such as pelvic inflammatory disease, miscarriage, postabortion sepsis, chorioamnionitis, threatened preterm labor, premature rupture of membranes, premature delivery, endometri-
Quick Response Code:

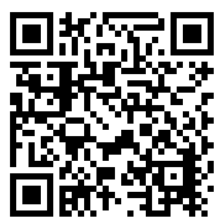

*Corresponding author: Franklin J Espitia De La Hoz, Universidad Militar Nueva Granada, Colombia

Received: 25 April, 2021

Published: 10 January, 2022

Citation: De La Hoz FJE. Efficacy And Safety of Nifuratel-Nystatin in The Treatment of Mixed Vaginitis, in Pregnant Women From Quindío, 2013-2017. Randomized Clinical Trial. Pregn Womens Health Care Int J. 2022;2(1):1-7. DOI: 10.53902/PWHCIJ.2022.02.000508 
tis and surgical wound infections, it can also lead to an increased risk of acquiring and transmitting the human immunodeficiency virus (HIV) as well as other sexually transmitted infections (STIs). ${ }^{7-9}$ The diagnosis of BV can be made clinically if the patient meets 3 of the 4 Amsel criteria. ${ }^{10}$ The Nugent score is also a reliable method of diagnosis commonly used in research studies. ${ }^{11}$ Vulvovaginal candidiasis (VVC) affects between 30-50\% of women; most cases are caused by Candida albicans, Candida glabrata or Candida krusei; ${ }^{12,13}$ around $50 \%$ of them will suffer a second episode, ${ }^{14}$ and $5-10 \%$ will have a recurrent VVC. ${ }^{14,15}$ In pregnancy, VVC reaches a prevalence of $26 \%$; $^{16}$ becoming an important cause of morbidity, since it causes abortion, low birth weight, chorioamnionitis, premature delivery and increased risk of seroconversion in HIV-negative women. ${ }^{17,18}$ The diagnosis of VVC is established with an adequate clinical history and vulvovaginal examination, supported by microscopy and, in a few cases, culture is needed. ${ }^{14,19}$

Trichomoniasis vaginitis (TV) in the US is reported in approximately 7 million new cases each year, with prevalence rates ranging from $3 \%$ in women, ${ }^{20}$ to $14 \%$ in adolescents, ${ }^{21} 13-36 \%$ in pregnant women, ${ }^{22,23} 38 \%$ in drug users ${ }^{24}$ and up to $47 \%$ in incarcerated pregnant women. ${ }^{25}$ The main complications among women include pelvic inflammatory disease, infection of the Skene and Bartholin glands, low birth weight, premature delivery, and premature rupture of membranes. ${ }^{26}$ In the diagnosis of TV, the fresh examination of vaginal discharge reports a variable sensitivity (62-92\%), with a specificity of 98\%; although the appropriate method, given its sensitivity (98\%) and specificity (100\%), is the culture in Roiron and Diamond broths. ${ }^{27,28}$ Mixed vaginitis is characterized by the simultaneous presence of two or more pathogens in the vagina, regardless of the clinical importance of the individual germs; candida vaginitis and trichomoniasis vaginitis, candida vaginitis and bacterial vaginosis, or candida vaginitis and aerobic micro-organism vaginitis usually coexist. ${ }^{29,30}$ Its prevalence in Latin America ranges between $12.82-33.9 \% .^{29,31}$

Traditional treatments for BV include metronidazole and clindamycin; with recurrence rates of $30 \%$ between 60 to 90 days after treatment, which increases with time (50\% in 12 months). ${ }^{32,33}$ In pregnant women with $\mathrm{BV}$, treatment with intravaginal clindamycin reports a therapeutic success of $93 \%$ compared to $87 \%$ with intravaginal metronidazole. ${ }^{34}$ In some studies, it is suggested that nifuratel has a better spectrum of activity against BV, showing highly active against Gardnerella vaginalis and Atopobium vaginae without affecting lactobacilli. ${ }^{33}$ In the treatment of VVC, there are two available therapeutic alternatives: polyenes and azoles, with cure rates ranging between $80-95 \% ; 32,35,36$ For its part, the nifuratel-nystatin combination has reported microbiological cure rates of $95 \% .{ }^{37}$ The treatment of choice for TV is metronidazole, with cure rates ranging between $86-97 \%{ }^{38,39}$ nifuratel shows strong antiprotozoal ac- tivity (trichomonicida), being safe and effective for the treatment of trichomoniasis. ${ }^{40}$ Nifuratel stands out for its antiprotozoal and antibacterial effect, with some fungicidal activity, without being active against the physiological vaginal flora; hence the nifuratel-nystatin combination is considered the drug of choice for the treatment of mixed vaginitis. ${ }^{30,41}$

Traditional therapies for the treatment of vaginitis/vaginosis are well established in clinical practice and are vital for the management of vaginal infections during pregnancy, in order to eliminate symptoms and prevent complications. By demonstrating the efficacy and safety of the nifuratel - nystatin combination versus the metronidazole - nystatin combination, it will allow patients access to equally effective drugs with fewer adverse effects and greater safety during pregnancy. Objective: to compare the efficacy and safety of the combination nifuratel - That is why the objective of this study was to compare the efficacy and safety of the combination nifuratel - nystatin with metronidazole - nystatin in the treatment of mixed vaginitis in pregnant women from Quindío, and to know its adverse effects.

\section{Materials and methods \\ Design and population}

Randomized, double-blind, controlled, two-arm, parallel-group, efficacy and safety clinical trial, which included pregnant women with a diagnosis of mixed vaginitis, over 18 years of age, pregnancy with a single fetus, without chronic diseases and without hypersensitivity to the drugs used; those who were randomly assigned to receive treatment, in a 1:1 ratio using block randomization (block size: 6) to receive nifuratel (500mg) - nystatin (200,000 IU) or metronidazole (500mg) - nystatin (100,000 IU) daily for six days. Between January 1, 2013 and December 31, 2017, in a highly complex private medical institution in Armenia (Colombia), which serves a population that belongs to the workers' contributory regime and to the subsidized regime of the comprehensive health system of Colombia. Patients classified as High Obstetric Risk (HOR), a history of urinary infection or STI in the last 2 weeks prior to being part of the study, inability to comply with therapy or continue follow-up, and those who did not agree to participate were excluded. All patients included in the study attended post-treatment control at 7 days and 1 month. In the selection of the sample size, the prevalence of mixed vaginitis, the level of significance $\alpha=0.05$ and the statistical power of 0.80 were considered. 78 patients were assigned to group "A" (nifuratel - nystatin), 75 patients were assigned to group "B" (metronidazole - nystatin).

\section{Procedure}

The women were recruited from the population of pregnant women who part of the prenatal control program. The information 
was compiled by three nurses who are part of the research team, duly trained in the process of recruiting patients and filling out forms; which surveyed women at the time of leaving the doctor's office, after verification of the diagnosis and the inclusion and exclusion criteria. The objectives of the study were explained to the patients that agreed to participate and they were asked to fill out the informed consent form; confidentiality of the handling of the information was guaranteed. A questionnaire was applied that included the socio-demographic and sexual and reproductive health characteristics. Symptoms, history, laboratory findings, and clinical examination data were reviewed in the medical records.

The diagnosis of bacterial vaginosis (BV), in this study, was made by jointly using the Nugent score (11), which give a score based on the proportion of Lactobacillus, Gardnerella vaginalis / Bacteroides and Mobiluncus spp., Where the BV reaches a score $\geq 7$, and with a score of 0-3 (normal microbiota), of 4-6 (intermediate microbiota); and following the Amsel criteria (10), that is, the presence of 3 or more of the following criteria:

1) Observation of guide or key cells (clue cells) in the Gram stain

2) $\mathrm{pH} \geq 4.5$

3) Positive amine test (fishy odor)

4) Fine and homogeneous vaginal discharge

Candidiasis was detected by observing yeasts plus hyphae or fresh pseudohyphae with $10 \% \mathrm{KOH}$, in Gram stain and by isolation in culture on Sabouraud agar and blood agar. The diagnosis of trichomona vaginalis was made by direct microscopic observation of fresh trophozoites with formulated acetic solution (SAF)/methylene blue, prolonged May-Grunwald Giemsa staining, and modified thioglycollate culture.

\section{Intervention}

Group "A" received a regimen of nifuratel $(500 \mathrm{mg})$ - nystatin (200,000 I.U.), a daily intravaginal dose at night at bedtime (Macmiror complex 500). Group "B" received a regimen of metronidazole (500mg) - nystatin (100,000 IU), a daily intravaginal dose at night at bedtime. The primary endpoints at one week consisted of assessment of clinical cure, defined by improvement experienced, and exploration of the Amsel criteria. The microbiological analysis was conducted one month after the end of the treatment, using the Nugent score, of two samples taken from the vaginal walls.

\section{Randomization and blinding}

The patients were randomized using an online system, in permuted blocks, for a total of 153 participants (with an allocation ratio of 1:1). The assigned code was expressed with 4 initials (corresponding to the first 2 letters of both names and the first 2 letters of the two surnames of each patient) and 3 numbers (corresponding to the first 3 numbers of the document). The randomization sequence was concealed in opaque envelopes sealed with each patient's code. The envelope contained the package with the drug, which was fully identified with the 3-digit number similar to the randomization code, so that neither the researcher nor the patient could know what drug it was. The information was recorded in a database elaborated in Excel $® 14.0$ (2011); which was verified by a professional nurse specialized in Health Auditing; outside the research team.

\section{Measured variables}

Socio-demographic variables were taken into account (age, race, marital status, occupation, place of origin, education, socio-economic stratum, affiliation to the Social Security System), height, weight, body mass index (BMI) and gestational age. Additionally, the different clinical manifestations of vaginal infection were studied. The outcome variables were clinical cure of symptoms at one-week, microbiological negativization at one month, and the presence of adverse events.

\section{Statistical analysis}

The quantitative variables were summarized with measures of central tendency and dispersion according to their distribution; qualitative variables in absolute numbers and proportions. The analysis was performed with the IBM SPSS Statistics 20.0 (2011) program.

\section{Ethical aspects}

This study was approved by the Ethics Committee for Research in Human Beings of the participating institution, in accordance with resolution 8430 of 1993 of the Ministry of Health of Colombia, and does not violate the guidelines of the Declaration of Helsinki of the world medical assembly on Ethical principles for medical research on human beings. The confidentiality of the information and the privacy of the patients were guaranteed.

\section{Results}

In the study period, 7,776 pregnant women were treated in the prenatal control program, of these, 2,451 (31.52\%) had BV, 29.51\% VVC, $6.25 \%$ TV, and $14.23 \%(n=1107 / 7776)$ mixed vaginitis. Of the 1107 women with mixed vaginitis, $329(29.71 \%)$ were invited to participate, who met the inclusion criteria, of which $32(9.72 \%)$ did not agree to participate, $84(25.53 \%)$ were pregnant. As for HOR, $47(14.28 \%)$ had a history of urinary infection or STI in the last 2 weeks, $13(3.95 \%)$ had difficulty complying with therapy or continuing follow-up, for which they were excluded; finally, the sample was made up of 153 pregnant women (46.5\%). The mean age of the participating population was $27.59 \pm 3.71$ years (minimum 18 years 
and maximum 42 years). $56.86 \%$ of the women obtained a body mass index greater than 25, interpreted as overweight or obesity, $76.47 \%$ had an urban origin, and $80.39 \%$ belonged to the contributory regime. Sociodemographic characteristics are described in Table 1. In the total population, in terms of gestation age at the time of diagnosis of mixed vaginitis, $11.76 \%$ were in the first trimester, $62.74 \%$ in the second trimester and $25.49 \%$ in the third trimester of pregnancy (minimum 12.5 and maximum 34.6 weeks). The mean gestational age in group "A" was $18.56 \pm 2.87$ weeks compared to $19.57 \pm 2.95$ weeks in group "B" ( $p=0.87)$. The most frequent symptom in both groups was the presence of vaginal discharge $(85.89 \%$ in Group "A" and 90.66\% in group "B", p>0.05), followed by bad odor $(84,61 \%$ vs. $84.00 \%, p>0.05)$ and dyspareunia $(73.07 \%$ vs. $72.00 \%, \mathrm{p}>0.05$ ). In none of the patients was the presence of genital ulcers detected Table 2 in the total population, the median in the presence of symptoms was 3 (range between 2 and 5); and the duration of symptoms was 12 days (range between 3 and 21).
At one week of follow-up, the cure rate for symptoms in group "A" was $84.61 \%$ and in group "B" it was $81.33 \%$, with no difference between the groups $(\mathrm{p}=0.91)$ The microbiological analysis corresponding to the month's control was negative in 71(91.02\%) of the 78 patients in group "A" versus 65(86.66\%) of the 75 patients in "B", $(\mathrm{p}=0.072)$. The recurrence rate in group "A" was $1.28 \%$ and in group "B" it was 5.33\%, but the difference was not significant ( $\mathrm{p}=0.37$ ). At one month of follow-up, in group "A", 6(7.69\%) patients still had an infection: three had candidiasis and three had BV, similar to group "B", where three still had candidiasis and three had BV. The first day in which the patients felt a sensation of healing of their symptoms, after starting the treatment, reached a median of 3 days (range between 2 and 5) in group "A" and 4 days (range between 3 and 5) in group "B" ( $p>0.05$ ). 88.46\% of women who received nifuratel-nystatin reported absence of vaginal discharge and absence of vaginal odor at day 7 , compared with $69.33 \%$ in the metronidazole - nystatin group ( $\mathrm{p}=0.024)$.

Table 1: Sociodemographic characteristics of pregnant women with mixed vaginitis. Quindío, Colombia (2013-2017).

\begin{tabular}{|c|c|c|c|}
\hline Variable & Group «A» $(n=78)$ & Group «A» $(n=75)$ & $\mathbf{p}$ \\
\hline Age & $26,71 \pm 4,25$ & $28,13 \pm 3,59$ & NS \\
\hline Weight (Kg) & $64,98 \pm 9,56$ & $63,35 \pm 8,97$ & NS \\
\hline Size (Mts) & $1,59 \pm 10,38$ & $1,57 \pm 11,46$ & NS \\
\hline BMI $\left(\mathrm{Kg} / \mathrm{m}^{2}\right)$ & $25,31 \pm 4,57$ & $25,62 \pm 3,97$ & NS \\
\hline \multicolumn{4}{|l|}{ Civil Status } \\
\hline Married \% & $25(32.05 \%)$ & $23(30.66 \%)$ & NS \\
\hline Common Law \% & $41(52.56 \%)$ & $38(50.66 \%)$ & NS \\
\hline Single \% & $12(15.38 \%)$ & $14(18.66 \%)$ & NS \\
\hline \multicolumn{4}{|l|}{ Occupation } \\
\hline Homemaker\% & 37 (47.43\%) & $34(45.33 \%)$ & NS \\
\hline Employed \% & $32(41.02 \%)$ & $33(44.00 \%)$ & NS \\
\hline Unemployed \% & $9(11.53 \%)$ & $8(10.66 \%)$ & NS \\
\hline \multicolumn{4}{|l|}{ Education } \\
\hline Primary & 7 (8.97 \%) & $8(10.66 \%)$ & NS \\
\hline Secondary & $12(15.38 \%)$ & $10(13.33 \%)$ & NS \\
\hline Technical & $26(33.33 \%)$ & $29(38.66 \%)$ & NS \\
\hline Professionals & $33(42.30 \%)$ & $28(37.33 \%)$ & NS \\
\hline \multicolumn{4}{|l|}{ Race } \\
\hline Hispanics \% & $42(53.84 \%)$ & $43(57.33 \%)$ & NS \\
\hline Afro Colombian \% & $28(35.89 \%)$ & $26(34.66 \%)$ & NS \\
\hline Indigenous \% & $8(10.25 \%)$ & $6(8.00 \%)$ & NS \\
\hline \multicolumn{4}{|l|}{ Socioeconomic status } \\
\hline High \% & $16(20.51 \%)$ & $17(22.66 \%)$ & NS \\
\hline Middle $\%$ & $52(66.66 \%)$ & $50(66.66 \%)$ & NS \\
\hline Low $\%$ & $10(12.82 \%)$ & $8(10.66 \%)$ & NS \\
\hline
\end{tabular}

Table 2: Clinical manifestations of pregnant women with mixed vaginistis Quindío, Colombia (2013-2017).

\begin{tabular}{|l|l|l|l|}
\hline Variable & Group «A» $(\mathbf{n = 7 8 )}$ & Group «A» $(\mathbf{n = 7 5 )}$ & $\mathbf{p}$ \\
\hline Grayish-white discharge & $67(85.89 \%)$ & $68(90.66 \%)$ & NS \\
\hline Erythema & $31(39.74 \%)$ & $34(45.33 \%)$ & NS \\
\hline Edema & $28(35.89 \%)$ & $25(33.33 \%)$ & NS \\
\hline Pruritus & $41(52.56 \%)$ & $38(50.66 \%)$ & NS \\
\hline Dysuria & $36(46.15 \%)$ & $37(49.33 \%)$ & NS \\
\hline Dyspareunia & $57(73.07 \%)$ & $54(72.00 \%)$ & NS \\
\hline Unpleasant smell ("fishy smell") & $66(84.61 \%)$ & $63(84.00 \%)$ & NS \\
\hline
\end{tabular}


Adverse events (AE) were not present in the nifuratel-nystatin group, while in the metronidazole - nystatin group 4 patients experienced vaginal irritation (5.33\%) and 3 manifested genital itching (4\%); which were mild and self-limited. There were no serious adverse events and there was no need to withdraw the drug in any of the groups.

\section{Discussion}

The vaginal infections found in this study of pregnant women were $31.52 \%$ for VB, $29.51 \%$ for VVC, $6.25 \%$ for TV and $14.23 \%$ for mixed vaginitis. The nifuratel - nystatin combination was able to produce an earlier healing sensation than the metronidazole nystatin combination, with a cure rate of symptoms one week after treatment of $84.61 \%$ vs. $81.33 \%(\mathrm{p}=0.91)$, while at one month, the microbiological analysis was negative in $91.02 \%$ vs. $86.66 \%$, $(p=0,072)$. The absence of vaginal discharge and absence of vaginal odor, at day 7 , in the nifuratel-nystatin group was $88.46 \%$ compared to $69.33 \%$ in the metronidazole-nystatin group ( $\mathrm{p}=0.024)$. The recurrence rate was $1.28 \%$ vs. $5.33 \%$, $(p=0.37)$. In relation to the fact that BV, VVC and TV are associated with an increased risk of contracting or transmitting the human immunodeficiency virus (HIV), as well as other sexually transmitted infections (STIs), secondary to the decrease in the levels of protective lactobacilli and increased levels of local inflammation; ${ }^{42-44}$ and on the other hand, they are also associated with adverse pregnancy outcomes (early spontaneous abortions, recurrent abortions, premature delivery and fetal death), ${ }^{45,46}$ as well as various gynecological complications. Given this scenario, the treatment of vaginal infections due to a mixed infection is not only mandatory, but it also becomes a real challenge given the frequent recurrences; $;^{29,48,49}$ This is why both timely diagnosis and adequate intervention are essential.

The results of the present study confirm the publication of Mendling et al., Who describe that nifuratel has a strong trichomonacidal activity equivalent to that of metronidazole, in addition to a broad spectrum of antibacterial action, against Gram negative and Gram positive microorganisms; being active against Chlamydia trachomatis and Mycoplasma spp., with some degree of activity against Candida spp. ${ }^{50}$ The results of Cepický et al. Could be extrapolated to those of this study, since the combination nifuratel $500 \mathrm{mg}$ - nystatin 200,000 IU exerted a high effect and a low number of relapses; all thanks to the fact that it behaves as a broad spectrum antimicrobial agent against the pathogens of the triad (fungi, bacteria, and T. vaginalis). ${ }^{30,40}$

Regarding the dose-effect relationship, our results are similar to those reported by Polatti et al., ${ }^{52}$ who documented that the best dose, in terms of risk / benefit ratio, was nifuratel 500mg - nystatin 200,000 IU once daily for 5 days; And despite its broad broad-spectrum antimicrobial property, this combination does not affect lactobacilli, ${ }^{53}$ which constitutes a clear advantage in the treatment of vaginal infections, especially during pregnancy. In multiple publications it has been reported that the nifuratel - nystatin combination guarantees a wide range of antimicrobial actions with rapid and notable symptomatic relief in patients with mixed vaginal infections of bacterial, fungal and protozoal origin, ${ }^{30,40,52}$ such as we have observed in this research. In a Cochrane review published in $2018^{54}$ they recommend that mixed vaginal infections should be treated effectively to reduce suffering and devastating consequences for women. This has led to the development of broad-spectrum antimicrobials, including the nifuratel-nystatin combination.

According to Cepický et al. ${ }^{30}$ and Polatti et al..$^{52}$ have shown that the nifuratel - nystatin combination is effective thanks to its exceptionally broad antibacterial, antifungal and trichomonacidal activity, making it the drug of choice in suspected mixed vaginal infection due to BV, VVC and TV.

The nifuratel-nystatin combination (Macmiror complex 500) can influence vaginitis of different etiology, which is why it is considered the most appropriate drug for mixed forms of vaginal infection; since its broad spectrum of action has been confirmed in vitro and in vivo, covering practically all the microorganisms responsible for genitourinary tract infections. ${ }^{55}$ As it has a very safe toxicological profile, it is not toxic and is well tolerated after intravaginal administration, in addition to lacking teratogenic effects; The nifuratel - nystatin combination can be used during pregnancy, as it shows a favorable risk/benefit ratio for the treatment of pregnant women with vulvovaginal infections. ${ }^{41,57,58}$

Knowing that in Colombia there are no previous studies on the use of the nifuratel-nystatin combination in the treatment of the most frequent vaginal infections that affect women of reproductive age; and knowing the scarce laboratory resources and trained personnel in our environment, syndromic treatment continues to be a rational approach for the care of women with vaginal infections. ${ }^{29}$ This syndromic approach, based on the assumption that genital tract infections share some common symptoms and signs, allows them to be assigned a specific etiology without the need for a laboratory test, ${ }^{59}$ which makes the combination nifuratel-nystatin the drug of choice. The main strength of this research is that it is the first study carried out in the country with this combination, as well as the processes for collecting information and monitoring patients, without losing follow-up, which favors quality, validity. and data reliability. As limitations we have the small number of patients included in each group and the reduced participation of the population belonging to the subsidized regime, where there could be an underestimation of both recurrences and resistance, since it is the population where the greatest risk factors prevail.

\section{Conclusion}

Both drug combinations were found to have comparable efficacy and similar safety results in the treatment of mixed vaginitis in 
pregnant women and therefore can be used interchangeably No adverse events were observed in the nifuratel-nystatin combination, reporting an earlier sensation of healing; therefore, it can be offered as a suitable alternative in the treatment of mixed vaginitis. Studies with a control group and random assignment in larger populations, pregnant and non-pregnant, are required to provide better evidence regarding this management.

\section{Thanks}

The author thanks both the participants and the staff of Hathor, Clínica Sexológica, without whose support it would not have been possible to conduct this study.

\section{Acknowledgements}

None.

\section{Funding}

This research did not receive any funding, it is the product of the author's financial, and resources obtained from his midwifery shifts.

\section{Conflict of Interest}

No conflict of interest.

\section{References}

1. Paladine HL, Desai UA. Vaginitis: Diagnosis and Treatment. Am Fam Physician. 2018;97(5):321-329.

2. Peebles K, Velloza J, Balkus JE, et al. High Global Burden and Costs of Bacterial Vaginosis: A Systematic Review and Meta-Analysis. Sex Transm Dis. 2019;46(5):304-311.

3. Tachawatcharapunya S, Chayachinda C, Parkpinyo N. The prevalence of bacterial vaginosis in 103 asymptomatic pregnant women during early third trimester and the pregnancy complications. Thai J Obstet Gynaecol. 2017;25:96-103.

4. Li XD, Tong F, Zhang XJ, et al. Incidence and risk factors of bacterial vaginosis among pregnant women: a prospective study in Maanshan city, Anhui Province, China. J Obstet Gynaecol Res. 2015;41(8):12141222.

5. Thomas T, Choudhri S, Kariuki C, et al. Identifying cervical infection among pregnant women in Nairobi, Kenya: limitations of risk assessment and symptom-based approaches. Genitourin Med. 1996;72(5):334-338.

6. Lata I, Pradeep Y, Sujata, et al. Estimation of the Incidence of Bacterial Vaginosis and other Vaginal Infections and its Consequences on Maternal/Fetal Outcome in Pregnant Women Attending an Antenatal Clinic in a Tertiary Care Hospital in North India. Indian J Community Med. 2010;35(2):285-289.

7. Eschenbach DA, Hillier S, Critchlow C, et al. Diagnosis and clinical manifestations of bacterial vaginosis. Am J Obstet Gynecol. 1988;158(4):819-828.

8. Hibbard JU, Hibbard MC, Ismail M, et al. Pregnancy outcome after expectant management of premature rupture of the membranes in the second trimester. J Reprod Med. 1993;38(12):945-951.

9. Rajshree S, Manju M, Leena S, et al. Effects of Bacterial Vaginosis on Perinatal Outcome. J Evol Med Dent Sci. 2014;3(8):2040-2046.
10. Amsel R, Totten PA, Spiegel CA, et al. Nonspecific vaginitis. Diagnostic criteria and microbial and epidemiologic associations. Am J Med. 1983;74(1):14-22.

11. Nugent RP, Krohn MA, Hillier SL. Reliability of diagnosing bacterial vaginosis is improved by a standardized method of gram stain interpretation. J Clin Microbiol. 1991;29(2):297-301.

12. Corsello S, Spinillo A, Osnengo G, et al. An epidemiological survey of vulvovaginal candidiasis in Italy. Eur J Obstet Gynecol Reprod Biol. 2003;110(1):66-72.

13. Foxman B, Muraglia R, Dietz JP, et al. Prevalence of recurrent vulvovaginal candidiasis in 5 European countries and the United States: results from an internet panel survey. J Low Genit Tract Dis. 2013;17(3):340345.

14. Sobel JD, Faro S, Force RW, et al. Vulvovaginal candidiasis: epidemiologic, diagnostic, and therapeutic considerations. Am J Obstet Gynecol. 1998;178(2):203-211.

15. Sobel JD. Vulvovaginal candidosis. Lancet. 2007;369(9577):19611971.

16. Sy O, Diongue K, Ahmed CB, et al. Candidoses vulvo-vaginales chez les femmes enceintes au centre hospitalier Mère et Enfant de Nouakchott (Mauritanie) [Vulvovaginal candidiasis in pregnant women in the Mère et Enfant Hospital center in Nouakchott, Mauritania]. J Mycol Med. 2018;28(2):345-348.

17. Holzer I, Farr A, Kiss H, et al. The colonization with Candida species is more harmful in the second trimester of pregnancy. Arch Gynecol Obstet. 2017;295(4):891-895.

18. Garcia Flores J, Cruceyra M, Cañamares M, et al. Candida chorioamnionitis: Report of two cases and review of literature. J Obstet Gynaecol. 2016;36(7):843-844.

19. Mendling W, Brasch J, Cornely OA, et al. Guideline: vulvovaginal candidosis (AWMF 015/072), S2k (excluding chronic mucocutaneous candidosis). Mycoses. 2015;58(Suppl 1):1-15.

20. Sutton M, Sternberg M, Koumans EH, et al. The prevalence of Trichomonas vaginalis infection among reproductive-age women in the United States, 2001-2004. Clin Infect Dis. 2007;45(10):1319-1326.

21. Krashin JW, Koumans EH, Bradshaw Sydnor AC, et al. Trichomonas vaginalis prevalence, incidence, risk factors and antibiotic-resistance in an adolescent population. Sex Transm Dis. 2010;37(7):440-444.

22. Franklin TL, Monif GR. Trichomonas vaginalis and bacterial vaginosis. Coexistence in vaginal wet mount preparations from pregnant women. J Reprod Med. 2000;45(2):131-134.

23. Rosenberg MJ, Davidson AJ, Chen JH, et al. Barrier contraceptives and sexually transmitted diseases in women: a comparison of female-dependent methods and condoms. Am J Public Health. 1992;82(5):669674.

24. Miller M, Liao Y, Gomez AM, et al. Factors associated with the prevalence and incidence of Trichomonas vaginalis infection among African American women in New York city who use drugs. J Infect Dis. 2008;197(4):503-509.

25. Shuter J, Bell D, Graham D, et al. Rates of and risk factors for trichomoniasis among pregnant inmates in New York City. Sex Transm Dis. 1998;25(6):303-307.

26. Silver BJ, Guy RJ, Kaldor JM, et al. Trichomonas vaginalis as a cause of perinatal morbidity: a systematic review and meta-analysis. Sex Transm Dis. 2014;41(6):369-376.

27. Van Der Pol B. Clinical and Laboratory Testing for Trichomonas vaginalis Infection. J Clin Microbiol. 2016;54(1):7-12.

28. Patel EU, Gaydos CA, Packman ZR, et al. Prevalence and Correlates of 
Trichomonas vaginalis Infection Among Men and Women in the United States. Clin Infect Dis. 2018;67(2):211-217.

29. Espitia De La Hoz FJ. Evaluación de la eficacia y seguridad del policresuleno en el tratamiento de la vaginitis mixta, Armenia, Colombia, 2017-2019. Estudio aleatorizado. Arch Med (Manizales). 2021;21(1):45-56.

30. Cepický P, Malina J, Líbalová Z, et al. “Smísené” a “nezaraditelné” vulvovaginitidy. Diagnostika a terapie vaginální aplikací nystatinu + nifuratelu ["Mixed" and "miscellaneous" vulvovaginitis: diagnostics and therapy of vaginal administration of nystatin and nifuratel]. Ceska Gynekol. 2005;70(3):232-237.

31. López M, Toro M, Guillén M. Citología de las infecciones cérvicovaginales. Rev Fac Farm Esp. 2001;42:27-34.

32. Workowski KA, Bolan GA. Centers for Disease Control and Prevention. Sexually transmitted diseases treatment guidelines, 2015. MMWR Recomm Rep. 2015;64(RR-03):1-137.

33. Bohbot JM, Vicaut E, Fagnen D, et al. Treatment of bacterial vaginosis: a multicenter, double-blind, double dummy, randomised phase III study comparing secnidazole and metronidazole. Infect Dis Obstet Gynecol. 2010;2010:705692.

34. Borisov I, Dimitrova V, Mazneĭkova V, et al. TerapeTVichni rezhimi za lechenie na bakterialnata vaginoza pri bremenni zheni [Therapeutic regimens for treating bacterial vaginosis in pregnant women]. Akush Ginekol (Sofiia). 1999;38(3):14-16.

35. Reef SE, Levine WC, McNeil MM, et al. Treatment options for vulvovaginal candidiasis, 1993. Clin Infect Dis. 1995;20(Suppl 1):S80-S90.

36. Lipsky MS, Waters T, Sharp LK. Impact of vaginal antifungal products on utilization of health care services: evidence from physician visits. $J$ Am Board Fam Pract. 2000;13(3):178-182.

37. Polatti F, Nappi RE, Brundu B, et al. Clinical study on the dose-effect relationship of a nifuratel-nystatin combination in the treatment of vulvo-vaginal infections. Arzneimittelforschung. 2003;53(10):730-737.

38. Thin RN, Symonds MA, Booker R, et al. Double-blind comparison of a single dose and a five-day course of metronidazole in the treatment of trichomoniasis. Br J Vener Dis. 1979;55(5):354-356.

39. Forna F, Gülmezoglu AM. Interventions for treating trichomoniasis in women. Cochrane Database Syst Rev. 2003;(2):CD000218.

40. Turanova EN, Skuratovich AA. TerapeTVicheskaia éffektivnost' ital'ianskogo preparata makmiror (Nifuratel) u bol'nykh trikhomonozom zhenshchin [Therapeutic effectiveness of the Italian preparation Makmiror (Nifuratel) in women with trichomoniasis]. Vestn Dermatol Venerol. 1972;46(7):78-80.

41. Mendling W, Mailland F. Microbiological and pharmaco-toxicological profile of nifuratel and its favourable risk/benefit ratio for the treatment of vulvo-vaginal infections. A review. Arzneimittelforschung. 2002;52(1):8-13.

42. Abbai NS, Reddy T, Ramjee G. Prevalent bacterial vaginosis infection-a risk factor for incident sexually transmitted infections in women in Durban, South Africa. Int J STD AIDS. 2016;27(14):1283-1288.

43. Schwebke JR, Lee JY, Lensing S, et al. Home Screening for Bacterial Vaginosis to Prevent Sexually Transmitted Diseases. Clin Infect Dis. 2016;62(5):531-536.

44. Gallo MF, Macaluso M, Warner L, et al. Bacterial vaginosis, gonorrhea, and chlamydial infection among women attending a sexually transmitted disease clinic: a longitudinal analysis of possible causal links. Ann Epidemiol. 2012;22(3):213-220.
45. Sangkomkamhang US, Lumbiganon P, Prasertcharoensuk W, et al. Antenatal lower genital tract infection screening and treatment programs for preventing preterm delivery. Cochrane Database Syst Rev. 2015; (2):CD006178.

46. Brocklehurst P, Gordon A, Heatley E, et al. Antibiotics for treating bacterial vaginosis in pregnancy. Cochrane Database Syst Rev. 2013;(1):CD000262.

47. Saleh AM, Abdalla HS, Satti AB, et al. Diagnosis of Trichomonous vaginalis by microscopy, latex agglutination, diamond's media, and PCR in symptomatic women, Khartoum, Sudan. Diagn Pathol. 2014;9:49.

48. Paulitsch A, Weger W, Ginter Hanselmayer G, et al. A 5-year (20002004) epidemiological survey of Candida and non-Candida yeast species causing vulvovaginal candidiasis in Graz, Austria. Mycoses. 2006; $49(6): 471-475$.

49. Sobel JD, Ferris D, Schwebke J, et al. Suppressive antibacterial therapy with $0.75 \%$ metronidazole vaginal gel to prevent recurrent bacterial vaginosis. Am J Obstet Gynecol. 2006;194(5):1283-1289.

50. Mendling W, Mailland F. Microbiological and pharmaco-toxicological profile of nifuratel and its favourable risk/benefit ratio for the treatment of vulvo-vaginal infections. A review. Arzneimittelforschung. 2002;52(1):8-13.

51. Cepický P, Malina J, Kuzelová M. Terapie aerobní vaginitis a klinicky nejasných prícin vulvovaginálního diskomfortu [Treatment of aerobic vaginitis and clinically uncertain causes of vulvovaginal discomfort]. Ceska Gynekol. 2003;68(6):439-442.

52. Polatti F, Nappi RE, Brundu B, et al. Clinical study on the dose-effect relationship of a nifuratel-nystatin combination in the treatment of vulvo-vaginal infections. Arzneimittelforschung. 2003;53(10):730-737.

53. Polatti F. Bacterial vaginosis, Atopobium vaginae and nifuratel. Curr Clin Pharmacol. 2012; 7(1):36-40.

54. Obiero J, Rulisa S, Ogongo P, et al. Nifuratel-Nystatin combination for the treatment of mixed infections of bacterial vaginosis, vulvovaginal candidiasis, and trichomonal vaginitis. Cochrane Database Syst Rev. 2018;2018(4):CD013012.

55. Zlatkov V, Karag'ozov I. Lechenie na vaginalni infektsii c Macmiror \& Macmiror Complex [The treatment of vaginal infections with Macmiror and Macmiror Complex]. Akush Ginekol (Sofiia). 1998;37(2):5759.

56. Karag'ozov I, Shopova E, Poriazov K, et al. Multitsentrichno prouchvane antimikrobniia efekt na Macmiror \& Macmiror Complex v lechenieto na vaginalnite infektsii [A multicenter study of the antimicrobial effect of Macmiror and Macmiror Complex in the treatment of vaginal infections]. Akush Ginekol (Sofiia). 1999;38(3):61-62.

57. Polish Gynecological Society Expert Group. Stanowisko Zespołu Ekspertów Polskiego Towarzystwa Ginekologicznego dotyczace preparatu Macmiror Complex 500 [Statement of the Polish Gynecological Society Expert Group on the use of Macmiror Complex 500]. Ginekol Pol. 2012;83(12):956-959.

58. Chamma Neto M, Teixeira RM. Tratamento das infecções por monília e trichomonas na gestação com nifuratel [Treatment of pregnancy infections caused by monilia and Trichomonas with nifuratel]. Rev Bras Med. 1969;26(10):599-601.

59. Pépin J, Sobela F, Khonde N, et al. The syndromic management of vaginal discharge using single-dose treatments: a randomized controlled trial in West Africa. Bull World Health Organ. 2006;84(9):729-738. 